\title{
Analysis on the Problems and Countermeasures of College Students' Time Management
}

\author{
Yang Wu \\ Zhongnan University of Economics and Law, Hubei, Wuhan, 430073
}

Keywords: college students, time management; problem analysis

\begin{abstract}
Time is one of the objective forms of material existence. It is an important element that everyone has a fair share of and realizes the value of life. Time is irreplaceable, irreversible, and non-renewable. Therefore, it is the most important resource in life. For college students, time management will have a direct impact on their study, quality of life, and mental state during their school years, and will have a profound impact on the realization of their long-term goals and the improvement of their social values. Its own time management makes it change from passive and natural use time to systematic, centralized, purposeful and planned active allocation of time to improve the efficiency of learning and life. However, in actual situation, there are still many problems in the time management of college students. Only by analyzing these problems and proposing specific solutions, can we improve the effectiveness of time management of college students. The paper mainly analyzes the problems existing in the time management of college students and proposes specific solutions.
\end{abstract}

\section{The Definition of Time and Time Management}

The so-called time refers to the continuous uninterrupted line composed of the past, the present and the future. The time has the characteristics of irreversible, non-stagnable, non-resilient, irreplaceable and non-renewable. It is these characteristics of time that determine its The most precious resource in the world. The so-called time management refers to controlling the time under the same amount of time conditions to improve the time utilization efficiency and effect. It can be seen that the time management of college students is to carry out planned and purposeful management and control for the daily life of college students, master the skills of scientific management time, improve the efficiency and effect of controlling the available time, and carry out their own personal life and study life. Reasonable arrangements to better achieve the desired goals. The main purpose of time management is to apply limited time to the process of achieving life goals and achieve better results, efficiency and efficiency. The so-called effect is the determined expectation result, the efficiency is obtained with the least cost or cost, and the performance is the best expected result with the least cost and cost. It can be seen that scientific and reasonable time management will have an important impact on the quality of life and the realization of life goals, and even decisive influence.

\section{The Problems of College Students' Time Management}

Specifically, the problems in the time management of college students are mainly reflected in the lack of planning, time management, poor execution, and procrastination in time management.

According to relevant survey data, most college students lack awareness of time management and have not formulated a scientific and systematic time management plan for time management. The weak concept of time makes it impossible to fully recognize the important value of time. It does not know how to cherish time, which leads to the most precious adolescence in life wasted in meaningless time, such as playing games, chasing dramas, online shopping and so on. The greatest harm to the lack of time management awareness is that it will form inertia, which in turn affects students' living habits, leading to a nausea cycle. The reasons for the weak sense of time management of college students include the following: students from the beginning of primary 
school to before entering the university, their time management is passive, lack of experience and awareness of active time management, so they can not manage their own time; secondly, many College students lack long-term employment planning, are unclear about their goals and efforts, and lack the necessary time management awareness in this stress-free life. Finally, although the school has developed vocational planning courses for students, its content is broad.

Although some college students have strong time management concepts and have the awareness of formulating time management plans, they are inefficient when implementing time management plans, and cannot guarantee the implementation results, mainly in the following aspects: First, time management plan The arrangement is unreasonable. Some college students' time management plans are not in line with their actual situation. They do not fully consider the unexpected situations and the feasibility of the implementation of the plan during the implementation of the plan. Some students are not even able to formulate a complete time plan, thus resulting in the entire time management. Plan execution is poor. Second, the goal of the time management plan is not clear. When formulating a time management plan, college students do not have the effect that the time management plan may achieve, and lack effective time management plan goals. Therefore, they lack motivation when implementing time planning. Again, the time allocation is unreasonable. The time in people's daily life will be divided into many pieces. The scientific time management plan must not only allocate a large amount of time reasonably, but also effectively use and arrange these time fragments to truly improve the efficiency of time management. However, college students ignore these scattered time when they allocate time. They do not follow the principle of "light, heavy, slow, and urgent" when they allocate time. This is also an important factor affecting the effectiveness of time management of college students. Finally, the implementation of the time management plan is not effective. The sense of time effectiveness will directly affect the effect of college students on the time management plan. Even if college students are implementing time management plans, the expected results are not satisfactory. College students lack sufficient confidence in the implementation of the plan and even believe that they do not have the ability to complete the time plan.

Procrastination is not only a negative psychological tendency, but also a harmful behavior habit. In time management, procrastination has an important negative impact on college students' daily life, work and study, and even mental outlook. Therefore, procrastination is time management. The phenomenon of procrastination in the daily work and life of college students can be seen everywhere, such as clothes washing again tomorrow, homework sitting tomorrow, participating in various activities late, late class, late night, and so on. Procrastination not only wastes a lot of time for students, but also directly affects the mental state of college students. The reasons for the procrastination of college students are very complicated. On the one hand, because students lack a rigorous learning attitude, they are eager for quick success in their study life, and they are unable to maintain a serious learning state. Once the learning effect is not as expected, they will become passive and slack. On the other hand, students' learning environment has many factors and difficulty in learning, which can lead to procrastination. Difficulties in learning tasks can make students feel fearful and contradictory, and external factors can also make college students with weak will lose their motivation to learn, such as online games, drama, online shopping, etc., leading to procrastination in time management.

\section{The Strategy to Improve the Effectiveness of College Students' Time Management}

In view of the problems existing in the time management of college students, it is suggested to strengthen the improvement from the following aspects to improve the effectiveness of time management of college students:

First, we must guide students to establish correct time values, integrate time management into theoretical study, practical teaching and life management, help college students establish correct time values; create a good time management atmosphere on campus, and enable students from all aspects. Recognize the true value of time, and help them achieve the success of learning and career through scientific and reasonable time management. Secondly, carry out target education, set up a 
"college career planning" system course, provide professional guidance for college students' career planning, and emphasize the level and pertinence in the curriculum setting, so that students can be based on their actual situation and professional characteristics. And the social environment to determine their own career pursuits, clear goals, develop a rational life plan, determine the direction of efforts, and improve the pertinence and feasibility of time management. Finally, special time management training is carried out to improve students' time management skills. Students have been dealing with the passive state of time management. In the university classroom, students should have systematic and clear time management guidance, teach the theory and practice of time management, master the skills of time management, and improve the effectiveness and effectiveness of time management.

College students should improve their self-discipline, resist external interference, and reasonably arrange time for college students to flexibly arrange their learning content according to their physiological characteristics and psychological characteristics. The more efficient the use of time, the better the individual's long-term habit of creating efficient time management. Efficient time is the most active and energetic stage of personal thinking. Learning and life are obviously more favorable, so students should complete the most important learning tasks in an efficient time, inefficient time can be used to complete relatively minor arrangements; and college students should refuse fatigue learning, so that work and rest can really improve time. Use efficiency to improve learning outcomes. In addition, students should also enhance their self-discipline ability to resist external interference. Entertainment and social work will take up a lot of learning time for students, especially smart phones, which will interfere with the life of college students, friends, microblogs, mobile games and so on. College students should enhance their self-discipline, go to quiet places, places without internet, and stay away from interference sources to reduce the interference of external factors on time management efficiency.

Time management should follow three principles, namely, the principle of positive initiative, the principle of plan control, the principle of practical development, etc., actively choose and determine the values of life, allocate time according to the individual's life goals, and continuously learn new time management methods and Technology is used in practice. When college students enter the school, they must strengthen the guidance of college students' time values, help students to establish a positive outlook on life and values, make them recognize the fierce social competition, enhance their sense of professional urgency, and make reasonable plans for their careers. Put more time and energy into your studies and skills. Parents of students should fully respect the students' autonomy and encourage students to decide their own lives. However, they do not interfere with the students' own life plans, and only correct them when necessary to prevent students from going astray. Pay attention to the skills and methods of time management. Everything can be done in one go, and things that can be done in one go should be done in one go, avoiding duplicating the same thing and wasting time. Reasonable use of fragmentation time, avoiding interference from mobile phones and networks to reduce time management efficiency; learning from the experience of students with better time management effects, eliminating the need to waste time, at least improving the habit of wasting time, summing up the failure of time management Reasons to improve the effectiveness of time management.

\section{Conclusion}

In short, time is a scarce and precious resource for each of us. For college students, time management is one of the life skills that they must master. It affects the study, life and physical and mental health of college students. For college students, time management is an important ability that must be possessed in studying and managing personal affairs. Therefore, time management is an indispensable part of higher education in China, and it is also to improve the overall quality and skills of college students. Of course, the cultivation of time management ability of college students cannot be accomplished overnight. It is a long and gradual process. Therefore, in the actual campus management process, both teachers and students must fully realize the importance of training time management skills and implement time management. To the student's entire life, study, and truly 
improve the effectiveness of student time management.

\section{References}

[1] Zhang Xiaofang. Sociological Analysis of College Students' Time Utilization Status_—A Survey of Undergraduates in Seven Universities in Beijing [D]. Beijing: Beijing Normal University, 2015:13

[2] Ding Hongyan. Intervention study on time management tendency of college students [D]. Wuhan: Central China Normal University, 2007: 7

[3] Zhang Zhijie, Huang Xiting, et al. Research on related factors of adolescents' time management tendency [J]. Psychological Science, 2016, (6): 649-653.

[4] Tang Dianquan. Analysis of Contemporary College Students' Extraordinary Time Behavioral Tendency_—A Survey Report of Some College Students in 25 Universities in China [J].Youth Exploration, 2012, (5):28.

[5] Xu Luning. Research on the Current Situation and Educational Strategies of College Students' Time Management [J].Science Chinese, 2015(6):245-246.

[6] Song Meizhen. On the current situation of college students' time management and coping strategies [J]. Fujian Forum: Social Science Education Edition, 2018(4): 374-375

[7] Li Linman. The Status Quo of College Students' Leisure Life and Educational Guidance Strategies [J]. School Party Construction and Ideological Education, 2013(12): 283-284 